\title{
Medication safety: opening up the black box
}

\section{Barbara Mintzes}

Correspondence to Dr Barbara Mintzes, School of Population and Public Health, University of British Columbia, \#307, 2176 Health Sciences Mall, Vancouver, British Columbia, Canada 604 822 7130:

Barbara.mintzes@ti.ubc.ca

Accepted 19 June 2013 Published Online First 5 July 2013

\section{CLinked}

- http://dx.doi.org/10.1136/ bmjqs-2012-001704
To cite: Mintzes B. BMJ Qual Saf 2013;22:702-704.
Medication-related adverse events are a major cause of disability and death, ${ }^{1}$ and one of the most common reasons that patients attend hospital emergency departments. ${ }^{2}$ Much of this harm is preventable, either because a less hazardous treatment is available, the medicine is not really needed, or it is inappropriate for this specific patient.

Many initiatives exist to improve medicine use. Schiff $e t a l^{3}$ call for a more judicious and precautionary approach to prescribing, with a focus on long-term as well as short-term health. To judge a medicine's net benefit to a patient, prescribers need comprehensive, accurate information on potential harmful as well as beneficial effects. Given the importance of medicines in treatment, information on harm is surprisingly inconsistent and elusive.

Approved product information describes adverse events experienced by patients in premarket studies as well as new safety signals once a drug is marketed. In their article, 'Speaking the same language? International variations in the safety information accompanying top-selling prescription drugs', Kesselheim et $a l^{4}$ describe differences in numbers and types of adverse events in product information for the same 20 top-selling medicines in the US, UK, Canada and Australia.

There is no reason to suspect that Americans, Australians, Canadians or the English differ in vulnerability to harm from medicines. As well as numbers of events, individual adverse events-including life-threatening harm-were inconsistently listed. The size of patient safety populations on which assessments were based ranged widely, from a median of 3563 in Australia to 7819 in the UK. ${ }^{4}$ This was product information for the same medicines, produced by the same manufacturers, and obtained at the same time.

Regulatory warnings of serious risks also differed: the US Food and Drug Administration (FDA) has issued boxed warnings for $15(75 \%)$ of the 20 medicines examined; Canada for nine; Australia for none; the UK does not use boxed warnings as a regulatory tool. The contrast is remarkable, as is the high frequency of US boxed warnings among these 20 best-selling medicines, given that only $45(8.2 \%)$ of 548 new medicines approved between 1975 and 1999 obtained black box warnings. ${ }^{5}$

US FDA black box warnings are reserved for problems linked to risks of death or serious injury. ${ }^{6}$ They can affect prescribing; antipsychotic drug use in elderly patients with dementia declined sharply following the black box warning of increased mortality. ${ }^{7}$ In one US analysis of 324548 outpatients' prescriptions, $10.4 \%$ of patients received drugs with black box warnings, but only $7 \%$ $(0.7 \%$ of the sample), received prescriptions that violated the warnings. ${ }^{8}$

US research on black box warnings is not necessarily transferable to other countries as implementation differs. In Canada, boxed warnings are not as prominent, and there is no available list of all medications with such warnings. In the USA, drugs with black box warnings may not be advertised to the public in 'reminder ads', which state the name of the drug but provide no health or risk information. ${ }^{9}$ Canada imposes no similar limits. Although Canadian law prohibits directto-consumer advertising of prescription drugs, 'reminder' ads have been allowed through a shift in administrative policy since late $2000 .{ }^{10}$ In 2005-2006, four of eight drugs in Canadian TV 'reminder ads' had US black box warnings, and six had Canadian safety advisories. ${ }^{11}$ This raises questions about regulatory safeguards. Physicians are influenced by patient requests for advertised medicines, ${ }^{12}$ and the public may be poorly informed of a medication's potential for harm.

In Australia, new boxed warnings are listed in a national bulletin, Medicines Safety Update. As Kesselheim et al ${ }^{4}$ note, 
Australia appears to have a high bar for boxed warnings, as none were issued for the 20 drugs they examined, versus 15 in the USA. ${ }^{13}$ Australia's more sparing use of boxed warnings could be more effective than US warnings if 'alert fatigue' is avoided. ${ }^{14}$ This is a testable hypothesis, but thus far these differing strategies have not been systematically compared.

Given the public health importance of safety warnings and national differences in approach, there is surprisingly little research outside the USA on their impacts. A systematic review of effectiveness of risk communication by the US FDA ${ }^{15}$ identified 49 studies, half of which $(n=25)$ were on black box warnings. The remainder were about advisories, safety alerts, or 'dear healthcare provider' letters. Although effects were variable, a few patterns emerged. Warnings affected new prescriptions more than ongoing use. Vague communications were ineffective, as were recommendations to monitor patients more intensively. Finally, physicians tended to be aware of safety advisories, but did not necessarily agree with them.

Disagreement may occur for a range of reasons, including limited knowledge of the rationale behind decisions. Regulators impose warnings on the basis of largely confidential signals, research results and expert advice. The US FDA is a notable exception in holding advisory committee meetings in public, but these are held at the agency's discretion. From 2004 to 2006, $14 \%$ of new black box warnings had been discussed in expert advisory committees. ${ }^{16}$

There is also inadequate public access to the postmarket safety evidence on which regulatory decisions are based. Manufacturers must provide regulators with periodic safety update reports (PSURS) after a medicine is approved, describing all new spontaneous adverse reaction reports and research results, but these reports are generally considered confidential. This evidence is especially important for best-selling medicines, such as the 20 examined by Kesselheim et al, ${ }^{4}$ which were tested on around 4000-8000 people premarket, but are used by hundreds of thousands if not millions of people postapproval. Many serious adverse effects are only discovered after approval, ${ }^{5}$ including rare and longer-term effects, and harm in the elderly, those with multiple illnesses, and other vulnerable groups excluded from premarket trials.

In 2010, the European Medicines Agency (EMA) shifted from its previous practice ${ }^{17}$ and began to allow public access on request to PSURs. This was put on hold in 2013, when two manufacturers initiated legal action against the EMA. ${ }^{18}$

Clinical trials are another source of information on harm, but reporting is often incomplete. Among 192 randomised controlled trials in seven clinical areas, only 39\% adequately reported adverse events. On average, one-third of a page was allocated to safety reporting. ${ }^{19}$ An analysis of all randomised control trials in six high-impact journals in $2006^{20}$ found that nearly half failed to report standard measures, such as numbers of patients who withdrew early due to adverse events.

Practicing physicians also receive incomplete safety information. Drug promotion has been shown to affect prescribing, an influence that is often underestimated. ${ }^{21}$ Pharmaceutical sales representatives are US physicians' most frequent information source on newly prescribed drugs. ${ }^{22}$ A study of the information that sales representatives provided to physicians in Canada, the USA and France found that serious adverse effects were mentioned in only $7 \%$ of promotions for drugs with boxed warnings. ${ }^{23}$ Not a single harmful effect or contraindication was mentioned in over half the promotions. Nevertheless, physicians generally judged the information quality positively.

Safety signals have a dampening effect on product sales, and this can lead to downplaying of evidence of harm, as occurred with rofecoxib, ${ }^{24}$ rosiglitazone ${ }^{25}$ and postmenopausal hormone therapy, ${ }^{26}$ among other examples. A controversy over a new class of diabetes drugs and a link to pancreatitis and pancreatic cancer highlights the role of manufacturers and also industrysponsored investigators, clinical experts and medical societies in countering emerging evidence of harm. ${ }^{27}$

What is the solution? Regulators require manufacturers to systematically test new medicines for market approval, and to carry out ongoing safety monitoring and postmarket studies on unresolved safety concerns. There are three main problems with this process: reliance on manufacturers to assess safety despite the inherent conflict of interest; confidentiality of research results; and the secrecy surrounding negotiations with manufacturers over safety alerts. A key solution is to open up this process, and the information on which it is based, to full public scrutiny.

Second, international comparative research is needed to establish best practices in medicines regulation from a public health perspective. In their analysis of differences in safety information in four countries, Kesselheim $e t a l^{4}$ point out that they could not judge which country's approach is better or worse because of the lack of comparative evaluative research. Drug regulation is a public health concern. Research on health impacts, and the political will to implement change as needed, need to be seen as public health priorities.

\section{Competing interests None.}

Provenance and peer review Not commissioned; internally peer reviewed.

\section{REFERENCES}

1 Lazarou J, Pomeranz BH, Corey PH. Incidence of adverse drug reactions in hospitalized patients: a meta-analysis of prospective studies. JAMA 1998;279:1200-5.

2 Zed PJ, Abu-Laban RB, Balen RM, et al. Incidence, severity and preventability of medication-related visits to the emergency department: a prospective study. CMAJ 2008;178:1563-9. 
3 Schiff GD, Galanter WL, Duhig J, et al. Principles of conservative prescribing. Arch Intern Med 2011;171:1433-1440.

4 Kesselheim A, Franklin J, Avorn J, et al. Speaking the same language? International variations in the safety information accompanying top selling prescription drugs. BMJ Qual Saf 2013;22:727-34.

5 Lasser KE, Allen PD, Woolhandler S, et al. Timing of new black box warnings and withdrawals for prescription medicinations. JAMA 2002;287:2215-20.

6 Murphy S, Roberts R. "Black Box" 1010: how the food and drug administration evaluates, communicates, and manages drug benefit/risk. J Allergy Clin Immunol 2006;117:34-9.

7 Dorsey ER, Rabbani A, Gallagher SA, et al. Impact of FDA black box advisory on antipsychotic medication use. Arch Intern Med 2010;170:96-103.

8 Lasser KE, Seger DL, Yu T, et al. Adherence to black box warnings for prescription medications in outpatients. Arch Intern Med 2006;166:338-44.

9 US Food and Drug Administration, Division of Drug Marketing Advertising and Communication. Guidance for industry - brief summary: disclosing risk information in consumer-directed print advertisements. Rockville, MD: US Department of Health and Human Services, 2004.

10 Gardner DM, Mintzes B, Ostry A. Direct-to-consumer prescription drug advertising in Canada: permission by default? CMAJ 2003;169:425-7.

11 Mintzes B, Morgan S, Wright JM. Twelve years' experience with direct-to-consumer advertising of prescription drugs in Canada: a cautionary tale. PLOS ONE 2009;4:e5699.

12 Kravitz RL, Epistein RM, Feldman MD, et al. Influence of patients' requests for direct-to-consumer advertised antidepressants: a randomised controlled trial. JAMA 2005;293:1995-2002.

13 Therapeutic Goods Administration, Australia. Searchable database of health professional product information and consumer medicines information. https://www.ebs.tga.gov.au/ (accessed 12 Jun 2013).

14 Buckley NA, Rossi S. Bringing greater transparency to "black box" warnings. Clin Toxicol 2011;49:448-51.

15 Dusetzina SB, Higashi AS, Dorsey R, et al. Impact of FDA drug risk communications on health care utilization and health behaviors. A systematic review. Med Care 2012;50:466-78.
16 Cook DM, Gurugubelli RK, Bero LA. Risk management policy and black-box warnings. A qualitative analysis of US FDA proceedings. Drug Saf 2009;32:1057-66.

17 European Medicines Agency. HMA/EMEA Recommendations on transparency. Recommendations on the handling of requests for access to Periodic Safety Update Reports (PSURs). London 23 November 2009. Doc Ref EMEA/743133/2009. http:// www.ema.europa.eu/docs/en_GB/document_library/ Regulatory_and_procedural_guideline/2009/12/ WC500016912.pdf (accessed Jun 2013).

18 Dyer C. European drug agency's attempts to improve transparency stalled by legal action from two US drug companies. BMJ 2013;346:f3588.

19 Ioannidis JPA, Lau J. Completeness of safety reporting in randomized trials. An evaluation of 7 medical areas. JAMA 2001;285:437-43.

20 Pitrou I, Boutron I, Ahmad N, et al. Reporting of safety results in published reports of randomized controlled trials. Arch Intern Med 2009;169:1756-61.

21 Norris P, Herxheimer A, Lexchin J, et al. Drug promotion: what we know what we have yet to learn. Geneva: World Health Organisation and Health Action International, 2005. http://apps.who.int/medicinedocs/pdf/s8109e/s8109e.pdf (accessed Jun 2013).

22 Anderson BL, Silverman GK, Loewenstein GF, et al. Factors associated with physicians' reliance on pharmaceutical sales representatives. Acad Med 2009;84:994-1002.

23 Mintzes B, Lexchin J, Sutherland J, et al. Pharmaceutical sales representatives and patient safety: a comparative prospective study of information quality in Canada, France and the United States. JGIM on-line 10 April 2013. http:/link.springer.com/ article/10.1007/s11606-013-2411-7

24 Waxman HA. The lessons of vioxx-drug safety and sales. $N$ Engl J Med 2005;352:25:2576-7.

25 Moynihan R. Rosiglitazone, marketing and medical science. BMJ 2010;340:785-9.

26 Tatsioni A, Siontis GCM, Ioannidis JPA. Partisan perspectives in the medical literature: a study of high frequency editorialists favoring hormone replacement therapy. J Gen Intern Med 2010;25:914-19.

27 Cohen D. Has pancreatic damage from glucagon suppressing diabetes drugs been underplayed? BMJ 2013;346:f3680. 